\title{
Two-point Stokes vector parameters of object field for diagnosis and differentiation of optically anisotropic biological tissues
}

O. V. Dubolazov

L. Trifonyuk

Yu. Marchuk

Yu. O. Ushenko

V. G. Zhytaryuk

O. G. Prydiy

L. Kushnerik

I. Meglinskiy 


\title{
Two-point Stokes vector parameters of object field for diagnosis and differentiation of optically anisotropic biological tissues
}

\author{
O.V. Dubolazova, L. Trifonyuk ${ }^{\mathrm{b}}$, Yu. Marchuk $^{\mathrm{b}}$, Yu.O. Ushenko ${ }^{\mathrm{a}}$, V.G. Zhytaryuk ${ }^{\mathrm{a}}$, O.G. \\ Prydiy $^{\text {a }}$ L. Kushnerik ${ }^{\text {a }}$ I. Meglinskiy \\ ${ }^{a}$ Chernivtsi National University, 2 Kotsyubinsky Str., Chernivtsi, 58012, Ukraine \\ ${ }^{\mathrm{b}}$ Bukovinian State Medical University, Chernivtsi, 58000, Ukraine \\ ${ }^{\mathrm{c}}$ University of Oulu, P.O. Box 4500, Oulu, Finland
}

\begin{abstract}
A new method of Stokes correlometry of polarization-inhomogeneous images of biological layers is presented. Analytic relations are determined for the modulus of complex parameters of the Stokes vector. A technique for measuring the coordinate distributions of the magnitude of the two-point modulus of the Stokes vector is proposed. Objective criteria for differentiating the optical anisotropy of polycrystalline urine films of healthy donors and patients with albuminuria have been found. An excellent level of balanced accuracy of differential diagnostics has been achieved.
\end{abstract}

Keywords: Stokes vector, biological tissues, diagnostics, polarimetry.

\section{INTRODUCTION}

The main theoretical positions of laser polarimetry of optically anisotropic biological layers are given in a series of publications ${ }^{1-29}$.

This research aims to study fundamental potentiality of the new Stokes-polarimetry approach to polarization-correlation mapping of microscopic images of polycrystalline layers of urine by determining the coordinate distributions of "twopoint" Stokes vector parameters, which were theoretically introduced for the first time by T.Setola, Ya.Tervo and A.T.Friberh ${ }^{30,31 .}$ As an applied aspect the possibility of differential Stokes-polarimetry diagnostics ${ }^{32-38}$ of the change of optical anisotropy of the urine films of healthy donors and patients with albuminuria will be discussed.

\section{THEORY OF THE METHOD}

To describe the correlation structure of the stationary distributions of the fields of complex amplitudes of laser light converted by optically anisotropic biological layers, one can use the following mutual spectral density matrix ${ }^{30,31}$

$$
W_{i, j}\left(r_{1}, r_{2}\right)=E_{i}^{*}\left(r_{1}\right) \cdot E_{j}\left(r_{2}\right), i, j=x, y
$$

Here $r_{1}$ and $r_{2}$ - the coordinates of the neighboring points in the field of laser radiation.

Relations for the analytic description of the module of two-point parameters of the Stokes vector were found

$$
\begin{gathered}
S_{1}=W_{x x}\left(r_{1}, r_{2}\right)+W_{y y}\left(r_{1}, r_{2}\right) ; \\
S_{2}=W_{x x}\left(r_{1}, r_{2}\right)-W_{y y}\left(r_{1}, r_{2}\right) ; \\
S_{3}=W_{x y}\left(r_{1}, r_{2}\right)+W_{y x}\left(r_{1}, r_{2}\right) ; \\
S_{4}=i\left[W_{y x}\left(r_{1}, r_{2}\right)+W_{x y}\left(r_{1}, r_{2}\right)\right]:
\end{gathered}
$$

Biosensing and Nanomedicine $\mathrm{X}$, edited by Hooman Mohseni, Massoud H. Agahi, Manijeh Razeghi, Proc. of SPIE Vol. 10352, 103520V · (c) 2017 SPIE · CCC code: 0277-786X/17/\$18 · doi: 10.1117/12.2273820 


$$
\begin{aligned}
& \left|S_{1}\right|=\sqrt{\left.1+\operatorname{tg}^{2} \rho_{1} \operatorname{tg}^{2} \rho_{2}+2 \operatorname{tg} \rho_{1} \operatorname{tg} \rho_{2} \cos \left(\delta_{2}-\delta_{1}\right)\right] ;} \\
& \left|S_{2}\right|=\sqrt{\left.1+\operatorname{tg}^{2} \rho_{1} \operatorname{tg}^{2} \rho_{2}-2 \operatorname{tg} \rho_{1} \operatorname{tg} \rho_{2} \cos \left(\delta_{2}-\delta_{1}\right)\right] ;} \\
& \left|S_{3}\right|=\sqrt{\left[1+\operatorname{ctg}^{2} \rho_{2} \operatorname{tg}^{2} \rho_{1}-2 \operatorname{ctg} \rho_{2} \operatorname{tg} \rho_{1} \cos \left(\delta_{2}-\delta_{1}\right)\right]} ; \\
& \left|S_{4}\right|=\sqrt{\left[1+\operatorname{ctg}^{2} \rho_{2} \operatorname{tg}^{2} \rho_{1}+2 \operatorname{ctg} \rho_{2} \operatorname{tg} \rho_{1} \cos \left(\delta_{2}-\delta_{1}\right)\right] ;}
\end{aligned}
$$

Here $\left|S_{i=1 ; 2 ; 3 ; 4}\right|$ - modulus.

\section{MATERIALS AND METHODS}

Measurement of the coordinate distributions of the values of $\left|S_{i=3}(\Delta x ; \Delta y)\right|$ and $\left|S_{i=4}(\Delta x ; \Delta y)\right|$ was carried out in the experimental arrangement of Stokes-polarimeter ${ }^{9,13,17}$ and were calculated by the following ratios

$$
\begin{aligned}
& \left|S_{3}\right|=\sqrt{\begin{array}{l}
\left.\sqrt{I_{0}\left(r_{1}\right) I_{90}\left(r_{2}\right)} \cos \delta_{2}+\sqrt{I_{0}\left(r_{2}\right) I_{90}\left(r_{1}\right)} \cos \delta_{1}\right]^{2}+ \\
+\left[\sqrt{I_{0}\left(r_{1}\right) I_{90}\left(r_{2}\right)} \sin \delta_{2}-\sqrt{I_{0}\left(r_{2}\right) I_{90}\left(r_{1}\right)} \sin \delta_{1}\right]^{2}
\end{array} ;} \\
& \left|S_{4}\right|=\sqrt{\begin{array}{l}
{\left[\sqrt{I_{0}\left(r_{2}\right) I_{90}\left(r_{1}\right)} \sin \delta_{1}+\sqrt{I_{0}\left(r_{1}\right) I_{90}\left(r_{2}\right)} \sin \delta_{2}\right]^{2}+} \\
+\left[\sqrt{I_{0}\left(r_{2}\right) I_{90}\left(r_{1}\right)} \cos \delta_{2}+\sqrt{I_{0}\left(r_{1}\right) I_{90}\left(r_{2}\right)} \cos \delta_{1}\right]^{2}
\end{array}} \\
& \delta(r)=\operatorname{arctg}\left[\left(\frac{S_{4}(r) S_{2}(r)}{S_{3}(r)}\right)\left(\frac{1+\frac{I_{90}(r)}{I_{0}(r)}}{1-\frac{I_{90}(r)}{I_{0}(r)}}\right)\right] .
\end{aligned}
$$

Here $I_{0}$ and $I_{90}$ - the intensities at the orientation of transmission plane of polarizer $0^{0}$ and $90^{\circ} ; \delta_{i}$ - phase shifts between the orthogonal components of the amplitude of the laser radiation in the points with coordinates $r_{1}$ and $r_{2}$.

\section{BRIEF DESCRIPTION OF THE RESEARCH OBJECTS}

Optically thin (attenuation coefficient $\tau \prec 0.01$ ) samples of polycrystalline layers of urine (geometrical thickness $l=10 \mu m \div 15 \mu m \quad 0.0079 \leq \tau \leq 0.0083$ ) of biological tissues of internals of two statistically significant (39 samples each) groups of patients - healthy ones and those with albuminaria.

\section{EXPERIMENTAL RESULTS AND DISCUSSION}

Fig. 1 - Fig. 4 show the SCP-maps of the modulus $\left|S_{i=3}(\Delta x ; \Delta y)\right|$ values distribution (Fig. 1, Fig. 3) and $\left|S_{i=4}(\Delta x ; \Delta y)\right|$ (Fig. 2, Fig.4) of microscopic images urine films of healthy donors (Fig. 1, Fig. 3) and patients with albuminuria (Fig. 2, Fig. 4). 

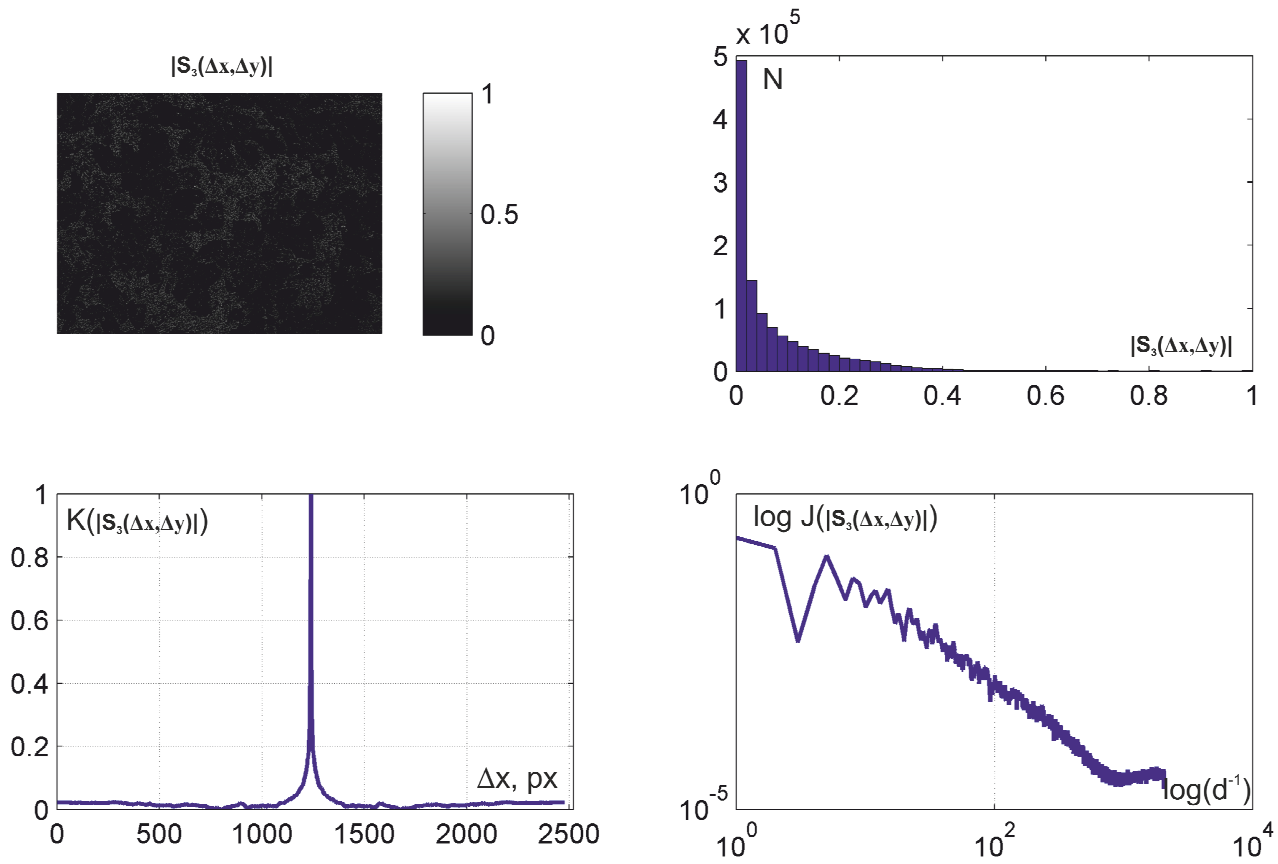

Figure 1. Maps (coordinate distributions (1), histograms (2), autocorrelation functions (3), logarithmic dependences of power spectra (4) of SCP modulus $\left|S_{i=3}(\Delta x ; \Delta y)\right|$ of polarization-inhomogeneous images of urine films of healthy donors.

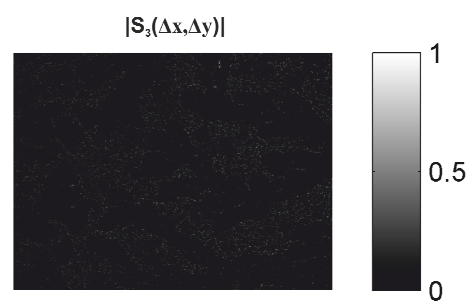

(1)

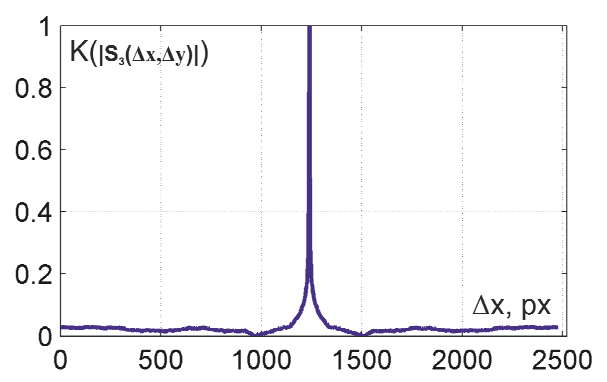

(3)
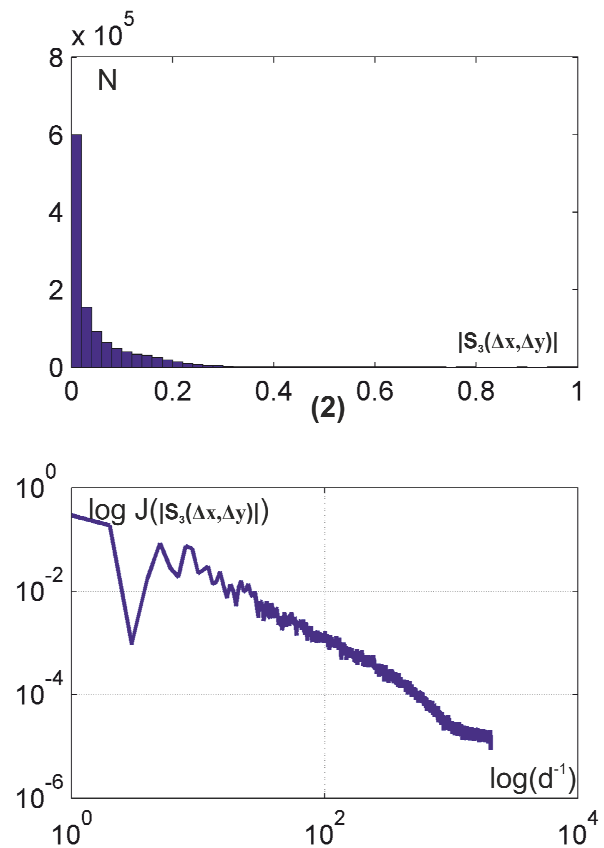

(4)

Figure 2. Maps (coordinate distributions (1), histograms (2), autocorrelation functions (3), logarithmic dependences of power spectra (4) of SCP modulus $\left|S_{i=3}(\Delta x ; \Delta y)\right|$ of polarization-inhomogeneous images of polycrystalline layers of urine of patients with albuminuria 


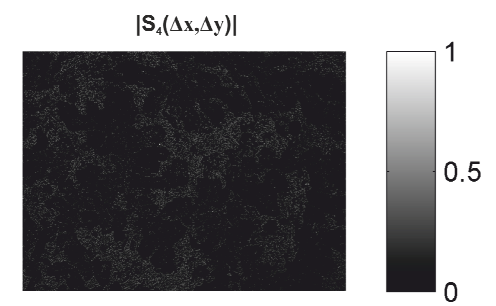

(1)

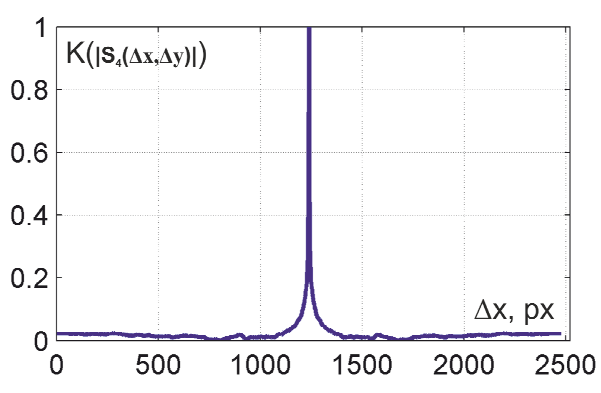

(3)
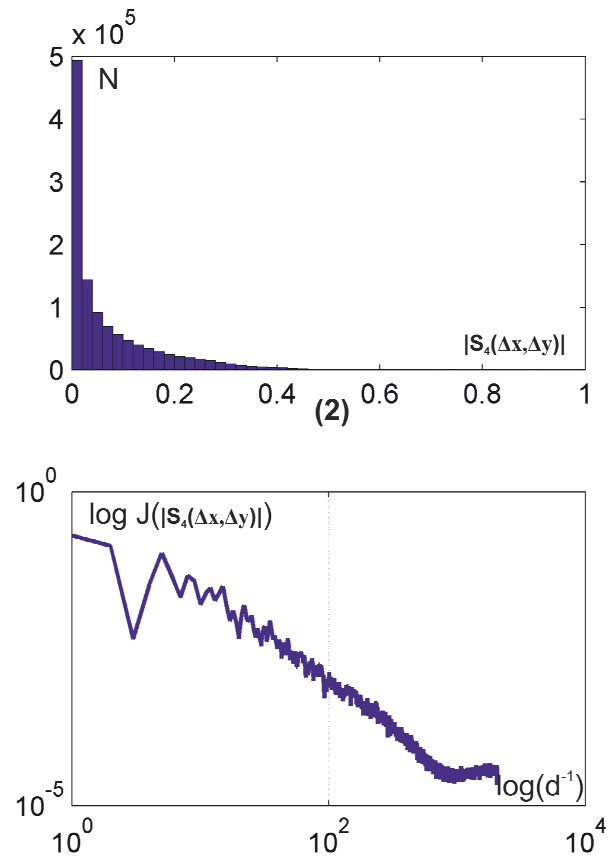

(4)

Figure 3. Maps (coordinate distributions (1), histograms (2), autocorrelation functions (3), logarithmic dependences of power spectra (4) of SCP modulus $\left|S_{i=4}(\Delta x ; \Delta y)\right|$ of polarization-inhomogeneous images of urine films of healthy donors

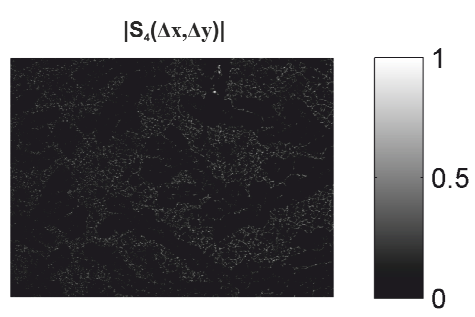

(1)

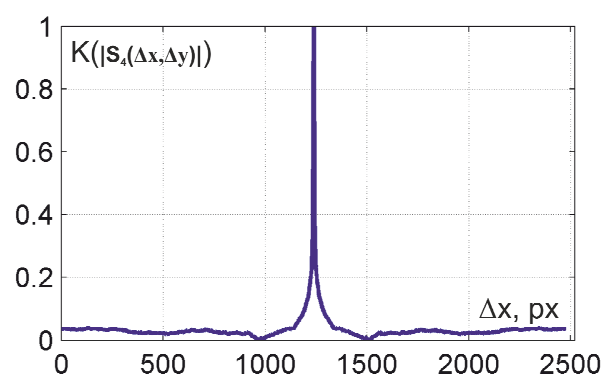

(3)
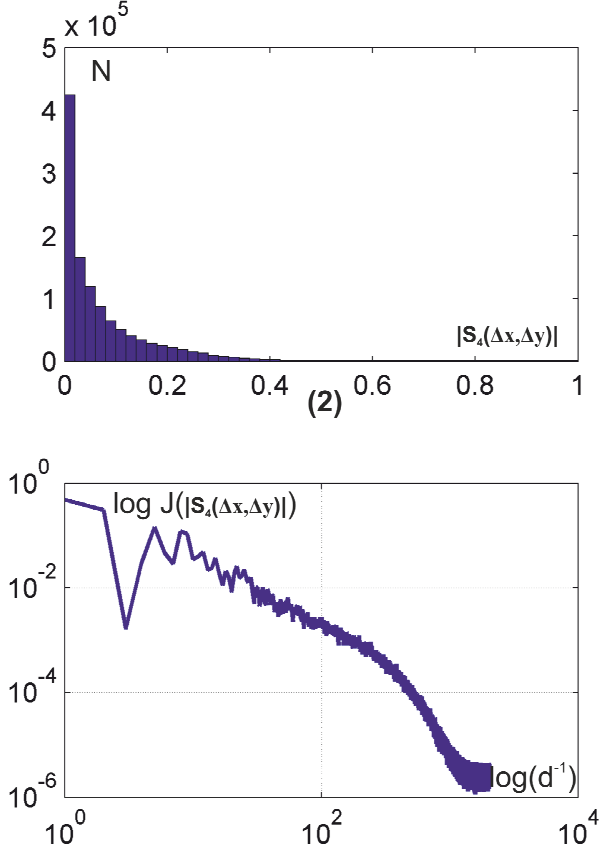

(4)

Figure 4. Maps (coordinate distributions (1), histograms (2), autocorrelation functions (3), logarithmic dependences of power spectra (4) of SCP modulus $\left|S_{i=4}(\Delta x ; \Delta y)\right|$ of polarization-inhomogeneous images of polycrystalline layers of urine of patients with albuminuria 
The potentiality of Stokes-correlometry differentiation of the two groups of polycrystalline layers of urine is quantitatively illustrated by the data presented in Table 1 .

Table 1 Statistical, correlation and fractal parameters of SCP modulus maps of polarization-inhomogeneous images of polycrystalline layers of urine

\begin{tabular}{|c|c|c|c|c|}
\hline Parameters & \multicolumn{2}{|c|}{$\left|S_{i=3}(\Delta x, \Delta y)\right|$} & \multicolumn{2}{|c|}{$\left|S_{i=4}(\Delta x, \Delta y)\right|$} \\
\hline Condition & $\begin{array}{c}\text { Normal } \\
(n=39)\end{array}$ & $\begin{array}{c}\text { Albuminuria } \\
(n=39)\end{array}$ & $\begin{array}{c}\text { Normal } \\
(n=39)\end{array}$ & $\begin{array}{c}\text { Albuminuria } \\
(n=39)\end{array}$ \\
\hline$Z_{1}$ & $0,037 \pm 0,0029$ & $0,019 \pm 0,0011$ & $0,77 \pm 0,031$ & $0,081 \pm 0,054$ \\
\hline$Z_{2}$ & $0,011 \pm 0,0013$ & $0,008 \pm 0,0006$ & $0,26 \pm 0,018$ & $0,086 \pm 0,0089$ \\
\hline$Z_{3}$ & $1,13 \pm 0,14$ & $3,37 \pm 0,26$ & $0,79 \pm 0,065$ & $2,27 \pm 0,29$ \\
\hline$Z_{4}$ & $3,12 \pm 0,25$ & $7,41 \pm 0,59$ & $0,92 \pm 0,079$ & $3,35 \pm 032$ \\
\hline$Z_{2}^{k}$ & $0,073 \pm 0,0055$ & $0,13 \pm 0,008$ & $0,065 \pm 0,006$ & $0,093 \pm 0,0087$ \\
\hline$Z_{4}^{k}$ & $2,14 \pm 0,18$ & $0,92 \pm 0,079$ & $1,56 \pm 0,14$ & $0,82 \pm 0,063$ \\
\hline$D^{f}$ & $0,24 \pm 0,019$ & $0,18 \pm 0,014$ & $0,35 \pm 0,024$ & $0,24 \pm 0,019$ \\
\hline
\end{tabular}

The data analysis revealed the following differences between the set of objective parameters that characterize the maps of SCP-modulus of polarization-inhomogeneous images:

- $\Delta Z_{1}=1.61-7.81$ times; $\Delta Z_{2}=1.68-2.81$ times; $\Delta Z_{3}=2.58-3,2$ times; $\Delta Z_{4}=2.12-4.48$ times;

- $\Delta Z_{2}^{k}=1.45-1.65$ times; $\Delta Z_{4}^{k}=1.78-2.43$ times;

- $\Delta D^{f}=1.24-1.44$ times.

The complex study found significantly greater accuracy of the methods of Stokes-correlometry in the differentiation of weak changes in optical anisotropy of of healthy donors and patients with albuminuria ( $90 \% \leq \max A c \leq 92 \%)$.

\section{CONCLUSION}

A new method of Stokes-correlometry - determination of the coordinate distributions of the modulus of "two-point" Stokes-vector parameters of polarization-inhomogeneous images of healthy donors and patients with albuminuria - is suggested and analytically substantiated.

Within the statistical, correlation and fractal analysis the objective criteria characterizing the SCP-maps of polarizationinhomogeneous microscopic images of two groups of healthy donors and patients with albuminuria are determined.

The comparative analysis of the objective statistical, correlation and fractal analysis of distributions of polarization "single-point" azimuth and ellipticity and "two-point" Stokes-vector parameters of polarization-inhomogeneous images of of healthy donors and patients with albuminuria under study demonstrated the excellent accuracy $(A c \succ 90 \%)$ of differential diagnostics of changes in optical anisotropy of rat's internal organs tissues by the Stokes-correlometry method.

\section{REFERENCES}

[1]. G. Müller et al., Eds., [Medical Optical Tomography: Functional Imaging and Monitoring], Vol. IS11, SPIE Press, Bellingham, Washington (1993).

[2]. G. Yao, L. V. Wang, "Two-dimensional depth-resolved Mueller matrix characterization of biological tissue by optical coherence tomography," Opt. Lett. , V.24, P. 537-539(1999).

[3]. S S Lu, R. A. Chipman, "Interpretation of Mueller matrices based on polar decomposition,” J. Opt. Soc. Am. A., Vol. 13, P.1106$1113(1999)$.

[4]. V.V.Tuchin, "Light scattering study of tissues," Physics-Uspekhi 40(5), 495-515 (1997). 
[5]. Ushenko, A. G., Burkovets, D. N., Ushenko, Y. A., "Polarization-phase mapping and reconstruction of biological tissue architectonics during diagnosis of pathological lesions," Optics and Spectroscopy, 93(3), 449-456 (2002).

[6]. Ushenko, A. G., "Polarization correlometry of angular structure in the microrelief pattern of rough surfaces. Optics and spectroscopy," 92(2), 227-229 (2002).

[7]. X. Wang, L.-H. Wang, "Propagation of polarized light in birefringent turbid media: a Monte Carlo study," J. Biomed. Opt., Vol. 7, P. 279-290 (2002).

[8]. Angelsky, O.V., Hanson, S.G., Maksimyak, P.P., Maksimyak, A.P., Zenkova, C.Yu., Polyanskii, P.V., Ivanskyi, D.I., "Influence of evanescent wave on birefringent microplates," Opt. Express 25, 2299-2311 (2017).

[9]. Angelsky, O. V., Bekshaev, A. Ya., Maksimyak, P. P., Maksimyak, A. P., Hanson, S. G., Kontush, S. M., "Controllable generation and manipulation of micro-bubbles in water with absorptive colloid particles by CW laser radiation," Opt. Express 25, 5232-5243 (2017).

[10]. Polyanskii, V.K., Angelsky, O.V., Polyanskii, P.V., "Scattering-induced spectral changes as a singular optical effect," Optica Applicata 32 (4), 843-848, (2002).

[11]. L. V. Wang and H.-I. Wu, [Biomedical Optics: Principles and Imaging], Wiley-Interscience, Hoboken, New Jersey (2007).

[12]. N. Ghosh, M. F. G. Wood, and I. A. Vitkin, [Polarized light assessment of complex turbid media such as biological tissues via Mueller matrix decomposition], Handbook of Photonics for Biomedical Science, V.V. Tuchin, Ed., pp. 253-282, CRC Press, Taylor \& Francis Group, London (2010).

[13]. O.V. Angelsky, A.G. Ushenko, Yu.A. Ushenko, V.P. Pishak, A.P. Peresunko, [Statistical, Correlation and Topological Approaches in Diagnostics of the Structure and Physiological State of Birefringent Biological Tissues], Handbook of Photonics for Biomedical Science, CRC Press, Taylor\&Francis group: Boca Raton, London, New York, 283-322, (2010).

[14]. D. Boas, C. Pitris, and N. Ramanujam, Eds., [Handbook of Biomedical Optics], CRC Press, Boca Raton, London, New York (2011).

[15]. N. Ghosh and I. A. Vitkin, "Tissue polarimetry: concepts, challenges, applications and outlook," J. Biomed. Opt. 16, 110801 (2011).

[16]. S. L. Jacques, [Polarized light imaging of biological tissues], Handbook of Biomedical Optics, D. Boas, C. Pitris, and N. Ramanujam, Eds., pp. 649-669, CRC Press, Boca Raton, London, New York (2011).

[17]. Y.A. Ushenko, T.M. Boychuk, V.T. Bachynsky, O.P. Mincer, [Diagnostics of Structure and Physiological State of Birefringent Biological Tissues: Statistical, Correlation and Topological Approaches], Handbook of Coherent-Domain Optical Methods, Springer Science+Business Media New York, p. 107-148 (2013).

[18]. Angelsky, O. V., Ushenko, A. G., Ushenko, Y. G., Tomka, Y. Y., "Polarization singularities of biological tissues images. Journal of biomedical optics," 11(5), 054030-054030 (2006).

[19]. Ushenko, A. G., "Laser diagnostics of biofractals," Quantum electronics, 29(12), 1078 (1999).

[20]. Ushenko, V. A., Gavrylyak, M. S., "Azimuthally invariant Mueller-matrix mapping of biological tissue in differential diagnosis of mechanisms protein molecules networks anisotropy," Proc. SPIE 8812, Biosensing and Nanomedicine VI, 88120Y ( 2013).

[21]. Ushenko, V. O., "Two-dimensional Mueller matrix phase tomography of self-similarity birefringence structure of biological tissues," Proc. SPIE 8487, Novel Optical Systems Design and Optimization XV, 84870W (2012).

[22]. Ushenko, V. A., Pavlyukovich, N. D., Trifonyuk, L., "Spatial-Frequency Azimuthally Stable Cartography of Biological Polycrystalline Networks International Journal of Optics,” Volume 2013 (2013).

[23]. Ushenko, Yu. A., Ushenko, V. A., Dubolazov, A. V., Balanetskaya, V. O., Zabolotna, N. I., "Mueller-matrix diagnostics of optical properties of polycrystalline networks of human blood plasma," Optics and Spectroscopy, Volume 112, Issue 6, pp 884-892 (2012). 
[24]. Ushenko, Yu. A., Dubolazov, A. V., Balanetskaya, V. O., Karachevtsev, A. O., Ushenko, V. A., "Waveletanalysis of polarization maps of human blood plasma," Optics and Spectroscopy, Volume 113, Issue 3, pp 332-343 (2012).

[25]. Angelsky, O. V., Bekshaev, A. Ya., Maksimyak, P. P., Maksimyak, A. P., Hanson, S. G., Zenkova, C. Yu., "Self-diffraction of continuous laser radiation in a disperse medium with absorbing particles," Optics Express 21(7), 8922-8938, (2013).

[26]. Angelsky, P. O., Ushenko, A. G., Dubolazov, A. V., Sidor, M. I., Bodnar, G. B., Koval, G., Trifonyuk, L., "The singular approach for processing polarization-inhomogeneous laser images of blood plasma layers," Journal of Optics, 15(4), 044030 (2013).

[27]. Dubolazov, A. V., Marchuk, V., Olar, O. I., Bachinskiy, V. T., Vanchuliak, O. Y., Pashkovska, N. V., Kostiuk, S. V., "Multiparameter correlation microscopy of biological fluids polycrystalline networks," In Eleventh International Conference on Correlation Optics, International Society for Optics and Photonics, pp. 90661Y-90661Y (2013).

[28]. Ushenko, O., Dubolazov, A., Balanets' ka, V., Karachevtsev, A., Sydor, M., "Wavelet analysis for polarization inhomogeneous laser images of blood plasma," Proc. SPIE. Vol. 8338 (2011).

[29]. Ushenko, V. A., O. V. Dubolazov, A. O. Karachevtsev, "Two wavelength Mueller matrix reconstruction of blood plasma films polycrystalline structure in diagnostics of breast cancer," Applied optics 53(10), B128B139 (2014).

[30]. Tervo, J., Setala, T., Friberg, A., "Degree of coherence for electromagnetic fields," Opt. Express 11, 11371143 (2003).

[31]. Tervo, J., Setala, T., Friberg, A., "Two-point Stokes parameters: interpretation and properties," Optics Letters 34(20), 3074-3076 (2009).

[32]. Ushenko, Yu. A., Gorskii, M. P., Dubolazov, A. V., Motrich, A. V., Ushenko, V. A., Sidor, M. I., "Spatial-frequency Fourier polarimetry of the complex degree of mutual anisotropy of linear and circular birefringence in the diagnostics of oncological changes in morphological structure of biological tissues," Quantum Electron, 42(8) (2012).

[33]. Angelsky, O. V., Bekshaev, A. Ya., Maksimyak, P. P., Maksimyak, A. P., Hanson, S. G., Zenkova, C. Yu., "Self-action of continuous laser radiation and Pearcey diffraction in a water suspension with light-absorbing particles," Optics Express 22(3), 2267-2277, (2014).

[34]. Angelsky, O. V., Bekshaev, A. Ya., Maksimyak, P. P., Maksimyak, A. P., Hanson, S. G., "Measurement of small light absorption in microparticles by means of optically induced rotation," Optics Express 23(6), 7152-7163 (2015).

[35]. Ushenko, Yu. A., Bachynsky, V. T., Vanchulyak, O. Ya., Dubolazov, A. V., Garazdyuk, M. S., Ushenko, V.A., "Jones-matrix mapping of complex degree of mutual anisotropy of birefringent protein networks during the differentiation of myocardium necrotic changes," Appl. Opt. 55, B113-B119 (2016).

[36]. Cassidy, J., "Basic concepts of statistical analysis for surgical research," Journal of Surgical Research 128, 199-206 (2005).

[37]. C. S. Davis, [Statistical methods of the analysis of repeated measurements], 744, New York: SpringerVerlag (2002).

[38]. A. Petrie, B. Sabin, [Medical Statistics at a Glance], pp. 157, Blackwell Publishing (2005). 